\title{
Assess the Knowledge and Practice among Cardiac Nurses about Patient Safety after Cardiac Catheterization, Tamilnadu
}

\author{
Karthi $\mathbf{R}^{1}$, Inigo Sherlin Joy $\mathrm{G}^{2}$, Jemima $\mathrm{M}^{3}$, Mahalakshmi $\mathrm{D}^{4}$ \\ ${ }^{1}$ Professor \& HOD, Dept of MSN, E.S. College of Nursing, Villupuram, Tamilnadu \\ ${ }^{2-4}$ Ist Year M.Sc., Nursing, E.S. College of Nursing, Villupuram, Tamilnadu.
}

Corresponding Author: Karthi R

\begin{abstract}
Background: Cardiac catheterization is an invasive procedure which is used in the diagnosis and treatment of several cardiac diseases. It may lead to several major and minor complications which may contribute to morbidity and mortality. Early recognition of complications and proper care is logically tied to taking action to receive prompt treatment and thus minimizing further complications.
\end{abstract}

Objectives: (i) To find out the level of knowledge and practice level of cardiac nurses related to patient safety after cardiac catheterization. (ii) To find the association between selected demographic variables with level of knowledge and practice of cardiac nurses regarding patient safety after cardiac catheterization.

Method: A survey was conducted in 30 convenient samples with a pre-validated questionnaire and an observational tool was also used in assessing the quality of care provided. The total period of the study was from January to February 2020. The study population was staff nurses from cardiology medical intensive care unit and cardiology medical ward.

Result: The findings show that in the level of knowledge among 30 samples the level of knowledge frequency and percentages. Adequate 22(73\%), moderately adequate 06(20\%), inadequate 02(7\%). Mean 7.53, standard deviation 1.33. In the level of practice among 30 samples the level of practice frequency and percentages. Good 20(67\%), average $08(27 \%)$, poor $02(6 \%)$. Mean 15.6, standard deviation 3.21. The findings shows that there is a significant association on knowledge level between demographic variables Additional qualification and Total year of experience at $\mathrm{p}<0.05$. In practice there is a significant association on practice level between demographic total year of experience at $\mathrm{p}<0.05$.

Conclusion: The Study concluded that most of the Staff nurses have adequate knowledge and good practice regarding care of patients after cardiac catheterization and there is an association on level of knowledge with demographic variables like additional qualification and total year of experience and in practice there is association with total year of experience.

Key Words: cardiac nurses, patient safety, cardiac catheterization.

\section{INTRODUCTION}

Cardiac catheterization is a valuable diagnostic procedure which does a comprehensive examination of how the heart and its blood vessels function. One or more catheters are inserted through a peripheral blood vessel in the antecubital artery or vein or femoral artery or vein with $\mathrm{x}$-ray guidance. This procedure gathers information such as adequacy of blood supply through the coronary arteries, blood pressures, blood flow throughout chambers of the heart, collection of blood samples, and $\mathrm{x}$ rays of the heart's ventricles or arteries. A test that can be performed on either side of the heart, cardiac catheterization checks for different functions in both the left and right sides. 
When testing the heart's right side, tricuspid and pulmonary valve function are evaluated, in addition to measuring pressures of and collecting blood samples from the right atrium, ventricle, and pulmonary artery. Left-sided heart catheterization is performed by way of a catheter through an artery which tests the blood flow of the coronary arteries, function of the mitral and aortic valves, and left ventricle. Some complications occur during the transfer of patients after cardiac catheterization or delayed or inadequately provided care.

Patient safety is defined as being free from accidental harm as a result of a health care encounter. It is the responsibility of the cardiac catheterization team to make that commitment to every patient and to each other. A well-functioning unit with a culture of safety, demonstrated clinical quality outcomes, and high internal/external customer satisfaction scores can avoid the risks associated with a less reliable unit. Cardiac catheterization is performed to evaluate coronary artery disease, valvular heart disease, congestive heart failure, and/or certain congenital (present at birth) heart conditions, such as atrial, septal defect or ventricular septal defect, when other less invasive types of diagnostic tests indicate the presence of one of these conditions. It is a common medical procedure that rarely causes serious problems. But complications can include bleeding, infection, pain where the catheter was inserted, and damage to blood vessels. Other less common complications of the procedure include an arrhythmia, damage to the kidneys, blood clots, heart attacks and low Blood pressure.

Cardiac catheterisation involves the insertion of a catheter into a vein or artery, usually from a groin or jugular access site, which is then guided into the heart. This procedure is performed for both diagnostic and interventional purposes. Diagnostic catheters are used to assess blood flow and pressures in the chambers of the heart, valves and coronary arteries and to assist in the diagnosis and management of congenital heart defects. Interventional catheters are used as an alternative to open-heart surgery when possible and are involved in closing ventricular and atrial septal defects via catheter device closure, expansion of narrowed passages (pulmonary stenosis), stent placement, ablation of abnormal electrical pathways and widening of existing openings (balloon atrial septectomy).

\section{STATEMENT OF THE PROBLEM}

A study to assess the knowledge and practice among cardiac nurses about patient safety after cardiac catheterization.

\section{OBJECTIVES:}

1. To identify the level of knowledge and practice of cardiac nurses regarding patient safety after cardiac catheterization.

2. To find the association between selected demographic variables with level of knowledge and practice of cardiac nurses regarding patient safety after cardiac catheterization.

\section{ASSUMPTION:}

$>$ The cardiac nurses may have adequate knowledge and practice of patient safety after cardiac catheterization.

$>$ The cardiac nurse may have Significance association between level of Knowledge and Practice with their selected socio Demographic Variables.

\section{MATERIAL AND METHODS Methodology:}

Descriptive survey approach was used for this study. A survey was conducted in 30 convenient samples with a prevalidated questionnaire and an observational tool was also used in assessing the quality of care provided.

\section{RESULT AND DISSCUSSION}

Level of Knowledge and Practice regarding patient safety after cardiac Catheterization among cardiac nurses. 
Karthi $R$ et.al. Assess the knowledge and practice among cardiac nurses about patient safety after cardiac catheterization, Tamilnadu.

Table- 1: Frequency and Percentage Level of Knowledge regarding patient safety after cardiac Catheterization among cardiac nurses. $\mathbf{N}=\mathbf{3 0}$

\begin{tabular}{|l|l|l|}
\hline \multirow{2}{*}{ LEVEL OF KNOWLEDEGE } & FREQUENCY & PERCENTAGE \\
\cline { 2 - 3 } & N & N\% \\
\hline ADEQUATE & 22 & $73 \%$ \\
\hline MODERATELY ADEQUATE & 6 & $20 \%$ \\
\hline INADEQUATE & 2 & $7 \%$ \\
\hline
\end{tabular}

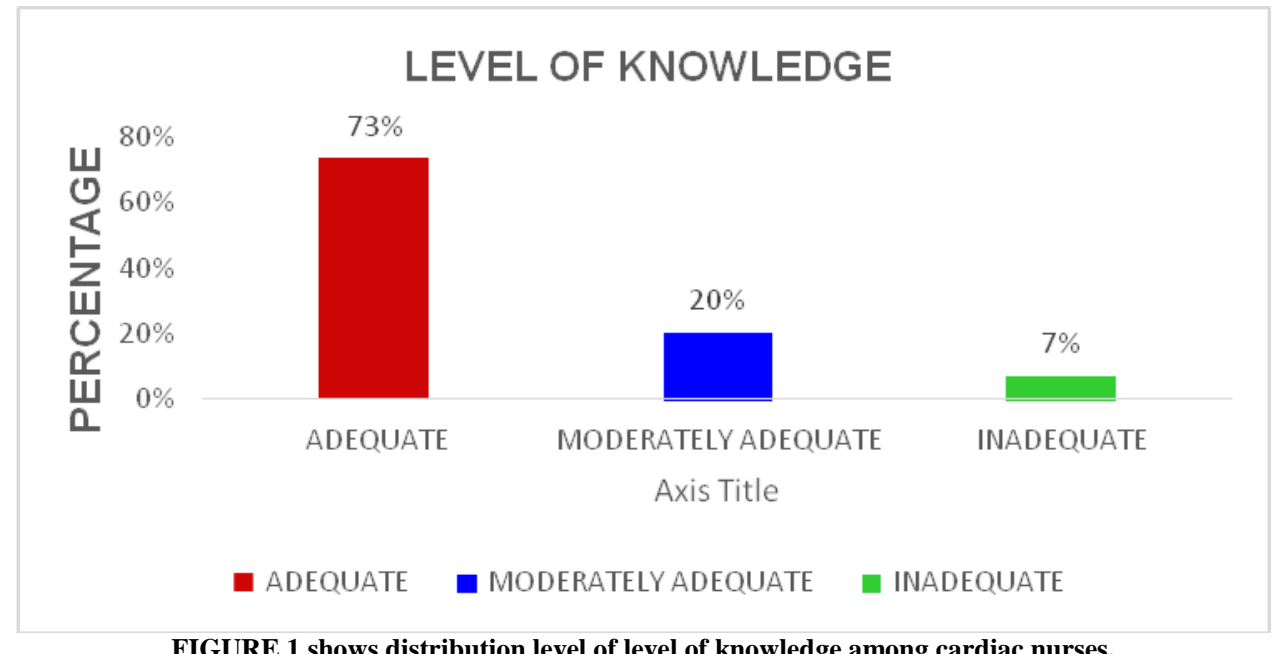

Table- 2: Frequency and Percentage Level of practice regarding patient safety after cardiac Catheterization among cardiac nurses $\mathbf{N}=\mathbf{3 0}$

\begin{tabular}{|l|l|l|}
\hline \multirow{2}{*}{ LEVEL OF PRACTICE } & FREQUENCY & PERCENTAGE \\
\cline { 2 - 3 } & N & N\% \\
\hline GOOD & 20 & $67 \%$ \\
\hline AVERAGE & 8 & $27 \%$ \\
\hline POOR & 2 & $6 \%$ \\
\hline
\end{tabular}

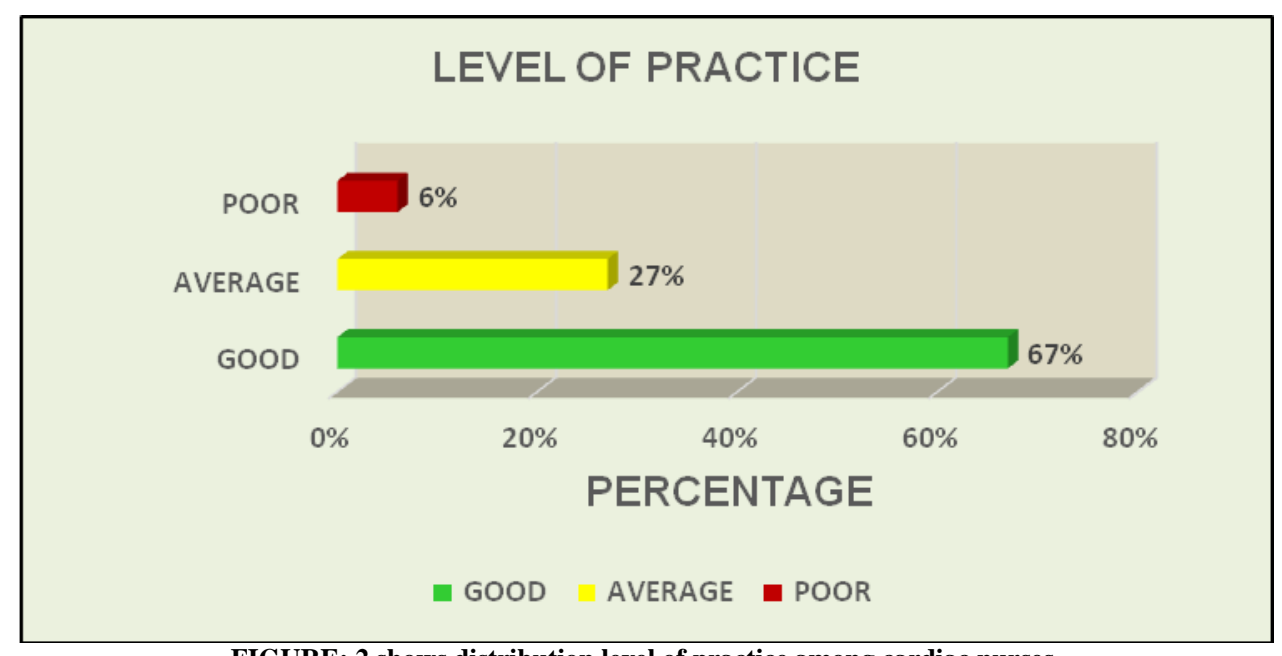

FIGURE: 2 shows distribution level of practice among cardiac nurses.

Table- 3: mean and Standard Deviation of knowledge and practice Level of practice regarding patient safety after cardiac Catheterization among cardiac nurses

\begin{tabular}{|l|l|l|}
\hline LEVEL & MEAN & STANDARD DEVIATION \\
\hline KNOWLEDGE & 7.53 & 1.33 \\
\hline PRACTICE & 15.6 & 3.21 \\
\hline
\end{tabular}

The table 3 shows that knowledge and practice mean and standard deviation.

Table-4 shows that there is a significant association between demographic variables knowledge level age, gender, qualification, additional qualification, place of work, year of experience at $\mathrm{p}<0.05$ and there is no significant age, gender, qualification, additional qualification, year of experience. Significance association on year of experience. 
Karthi $R$ et.al. Assess the knowledge and practice among cardiac nurses about patient safety after cardiac catheterization, Tamilnadu.

Table-4: Association of level of knowledge regarding patient safety after cardiac catheterization among cardiac nurses with their selected demographic variables.

\begin{tabular}{|c|c|c|c|c|c|c|}
\hline S.NO & DEMOGRAPHIC VARIABLES & Adequate & Moderate & Inadequate & Chi Square & P Value \\
\hline 1 & AGE & & & & \multirow{5}{*}{$\begin{array}{l}3.971 \\
D F=6\end{array}$} & \multirow{5}{*}{$\begin{array}{l}0.68 \\
\text { NS }\end{array}$} \\
\hline & a) $20-29$ & 16 & 4 & 0 & & \\
\hline & b) 30-39 & 4 & 1 & 1 & & \\
\hline & c) $40-49$ & 2 & 1 & 1 & & \\
\hline & d) 50 years and above & - & - & - & & \\
\hline \multirow[t]{3}{*}{2} & GENDER & & & & \multirow{3}{*}{$\begin{array}{l}0.948 \\
\mathrm{DF}=2\end{array}$} & \multirow{3}{*}{$\begin{array}{l}0.62 \\
\text { NS }\end{array}$} \\
\hline & a) male & 5 & 2 & 0 & & \\
\hline & b) female & 17 & 4 & 2 & & \\
\hline \multirow[t]{4}{*}{3} & QUALIFICATION & & & & \multirow{4}{*}{$\begin{array}{l}1.26 \\
D F=4\end{array}$} & \multirow{4}{*}{$\begin{array}{l}0.87 \\
\text { NS }\end{array}$} \\
\hline & a)DGNM & 10 & 4 & 1 & & \\
\hline & b)B.sc nursing & 10 & 2 & 1 & & \\
\hline & c) M.sc nursing & 2 & 0 & 0 & & \\
\hline \multirow[t]{3}{*}{4} & ADDITIONAL QUALIFICATION & & & & \multirow{3}{*}{$\begin{array}{l}20.65 \\
\mathrm{DF}=2\end{array}$} & \multirow{3}{*}{$\begin{array}{l}0.03 \\
\text { NS }\end{array}$} \\
\hline & a) yes, specify.... & 20 & 5 & 1 & & \\
\hline & b) no & 2 & 1 & 1 & & \\
\hline \multirow[t]{3}{*}{5} & PLACE OF WORK & & & & \multirow{3}{*}{$\begin{array}{l}0.45 \\
D F=2\end{array}$} & \multirow{3}{*}{$\begin{array}{l}0.80 \\
\mathrm{~S}\end{array}$} \\
\hline & $\mathrm{CCU}$ & 14 & 3 & 1 & & \\
\hline & CMW & 8 & 3 & 1 & & \\
\hline \multirow[t]{5}{*}{6} & TOTAL YEARS OF EXPERIENCE & & & & \multirow[b]{4}{*}{$\mathrm{DF}=6$} & \multirow{4}{*}{$\begin{array}{l}0.06 \\
\text { NS }\end{array}$} \\
\hline & a) $1-5$ & 19 & 3 & 1 & & \\
\hline & b)6-10 & 2 & 3 & - & & \\
\hline & c)11-15 & 1 & 0 & 1 & & \\
\hline & d) 15 years and above & - & - & - & & \\
\hline
\end{tabular}

Table-5: Association of practice regarding patient safety after cardiac catheterization among staff nurses with their selected demographic variables.

\begin{tabular}{|c|c|c|c|c|c|c|}
\hline S.NO & DEMOGRAPHIC VARIABLES & Good & Average & Poor & Chi Square & P Value \\
\hline 1 & AGE & & & & \multirow{5}{*}{$\begin{array}{l}8.6375 \\
D F=6\end{array}$} & \multirow{5}{*}{$\begin{array}{l}0.19 \\
\text { NS }\end{array}$} \\
\hline & a) 20-29 & 10 & 4 & 1 & & \\
\hline & b) $30-39$ & 5 & 2 & 0 & & \\
\hline & c) $40-49$ & 5 & 2 & 1 & & \\
\hline & d) 50 years and above & - & - & - & & \\
\hline \multirow[t]{3}{*}{2} & GENDER & & & & \multirow{3}{*}{$\begin{array}{l}0.931 \\
\mathrm{DF}=2\end{array}$} & \multirow{3}{*}{$\begin{array}{l}0.63 \\
\text { NS }\end{array}$} \\
\hline & a) male & 4 & 2 & 1 & & \\
\hline & b) female & 16 & 6 & 1 & & \\
\hline \multirow[t]{4}{*}{3} & QUALIFICATION & & & & \multirow{4}{*}{$\begin{array}{l}2.34 \\
\mathrm{DF}=4\end{array}$} & \multirow{4}{*}{$\begin{array}{l}0.67 \\
\text { NS }\end{array}$} \\
\hline & a)DGNM & 10 & 4 & 1 & & \\
\hline & b)B.sc nursing & 10 & 2 & 1 & & \\
\hline & c) M.sc nursing & 0 & 2 & 0 & & \\
\hline \multirow[t]{3}{*}{4} & ADDITIONAL QUALIFICATION & & & & \multirow{3}{*}{$\begin{array}{l}4.58 \\
D F=2\end{array}$} & \multirow{3}{*}{$\begin{array}{l}0.10 \\
\text { NS }\end{array}$} \\
\hline & a) yes, specify.... & 19 & 6 & 1 & & \\
\hline & b) no & 1 & 2 & 1 & & \\
\hline \multirow[t]{3}{*}{5} & PLACE OF WORK & & & & \multirow{3}{*}{$\begin{array}{l}0.101 \\
D F=2\end{array}$} & \multirow{3}{*}{$\begin{array}{l}0.95 \\
S\end{array}$} \\
\hline & $\mathrm{CCU}$ & 12 & 5 & 1 & & \\
\hline & CMW & 8 & 3 & 1 & & \\
\hline \multirow[t]{5}{*}{6} & TOTAL YEARS OF EXPERIENCE & & & & \multirow{5}{*}{2.092} & \multirow{5}{*}{$\begin{array}{l}0.91 \\
\text { NS }\end{array}$} \\
\hline & a) $1-5$ & 16 & 6 & 1 & & \\
\hline & b) $6-10$ & 2 & 2 & 1 & & \\
\hline & c) $11-15$ & 2 & 0 & 0 & & \\
\hline & d) 15 years and above & - & - & - & & \\
\hline
\end{tabular}

Table-5 shows that there is a significant association between demographic variables practice level age, gender, qualification, additional qualification, place of work, year of experience at $\mathrm{p}<0.05$ and there is no significant age, gender, qualification, additional qualification, year of experience. Significance association on year of experience.

\section{DISCUSSION}

The first objectives of the study to identify the knowledge level of nurses regarding patient safety after cardiac catheterization.

The findings show that in the level of knowledge among 30 samples the level of knowledge frequency and percentages. Adequate 22(73\%), moderately adequate 
Karthi $R$ et.al. Assess the knowledge and practice among cardiac nurses about patient safety after cardiac catheterization, Tamilnadu.

06(20\%), inadequate 02(7\%). Mean 7.53, standard deviation 1.33 .

The findings show that in the level of practice among 30 samples the level of practice frequency and percentages. Good $20(67 \%)$, average $08(27 \%)$, poor $02(6 \%)$. Mean 15.6, standard deviation 3.21.

The second objectives of the study to find the association between selected demographic variables with level of knowledge and practice of cardiac nurses regarding patient safety after cardiac catheterization.

The findings shows that in the level of knowledge among 30 samples there is a significant association between demographic variables knowledge level age, gender, qualification, additional qualification, place of work, year of experience at $\mathrm{p}<0.05$ and there is no significant age, gender, qualification, additional qualification, year of experience. Significance association on year of experience.

The findings shows that in the level of practice among 30 samples there is a significant association between demographic variables practice level age, gender, qualification, additional qualification, place of work, year of experience at $\mathrm{p}<0.05$ and there is no significant age, gender, qualification, additional qualification, year of experience. Significance association on year of experience.

\section{CONCLUSION}

The Study concluded that most of the cardiac nurses have adequate knowledge and good practice regarding care of patients after cardiac catheterization and there is an association on level of knowledge with demographic variables like additional qualification and total year of experience and in practice there is association with total year of experience.

\section{Acknowledgement: None}

Conflict of Interest: None

\section{Source of Funding: None}

\section{Ethical Approval: Approved}

\section{REFERENCES}

1. Anderson $\mathrm{K}$, Bregendahl $\mathrm{M}$, Kaestel $\mathrm{H}$, Skriver M, Ravkilde J. Haematoma after coronary angiography and percutaneous coronary intervention via the femoral artery frequency and risk factors. Eur J Cardiovasc Nurs.2005;4:123-127.

2. Barkman A, Lunse CP. The effect of early ambulation on patient comfort and delayed bleeding after cardiac angiogram: a pilot study. Heart Lung. 1994;23:112-117.

3. Best DG,PikeR,GraingerP,East wood CA,Carroll K.A Prospective study of early ambulation 90 minutes post left heart catheterization using a retrospective comparison group.Can $\mathrm{J}$ Cardiovasc Nurs.2010:20(4):15-20.

4. Dangas G, Mehran R, Kokolis S, et al. Vascular complications after percutaneous coronary interventions following hemostasis with manual compression versus arteriotomy closure devices. J Am Coll Cardiol. 2001;38:638-641

5. Duffin DC, Muhlestein JB, Allison SB, et al. Femoral arterial puncture management after percutaneous coronary procedures: a comparison of clinical outcomes and patient satisfaction between manual compression and two different vascular closure devices. $\mathbf{J}$ Invasive Cardiol. 2001;13:354-362.

6. Dumont JP, Keeling AW, Bourguignon C, Sarembock IJ, Turner M. Predictors of vascular complications post diagnostic cardiac catheterization and percutaneous coronary interventions. Dimens Crit Care Nurs.2006;25(3):137-142.

7. Eggebrecht $\mathrm{H}$, Haude $\mathrm{M}$, vonBirgelen $\mathrm{C}$, et al. Early clinical experience with the 6french Angio Seal device: immediate closure of femoral Eidt JF, Habibipour S, Saucedo JF, et al. Surgical complications from hemostatic puncture closure devices. Am J Surg.1999;178:511-516.

8. Fowlow B, Price P, Fung T. Ambulation after sheath removal: a comparison of 6 and 8 hours of bed rest after sheath removal in patients following a PTCA procedure. Heart Lung. 1995;24:28-37.

9. Gerckens U, Cattelaens N, Lampe E, Grube E. Management of arterial puncture site 
Karthi $R$ et.al. Assess the knowledge and practice among cardiac nurses about patient safety after cardiac catheterization, Tamilnadu.

after catheterization procedures: evaluating a suture mediated closure device. AmJCardiol.1999;83:1658-1663.

10. Harper JP.Post diagnostic cardiac catheterization ; development and evaluation of an evidence based standard of care.J nurses Staff Dev.Nov-Dec2007;23(6):27176

11. Herntzen M P,StraureBE.Peripheral arterial complications after heart catheterization. Herz.1998;23(1):4-20.
How to cite this article: Karthi R, Inigo Sherlin Joy G, Jemima M et.al. Assess the knowledge and practice among cardiac nurses about patient safety after cardiac catheterization, Tamilnadu. International Journal of Research and Review. 2021; 8(4): 220-225. DOI: https://doi.org/ 10.52403/ijrr.20210429 